\title{
Taiwanese Students' Considering Factors and Practical Suggestions Toward Studying Abroad in New Southbound Policy Countries
}

\author{
Yu-Hsien Sung ${ }^{1,2} \&$ Hsien-Ming $\operatorname{Lin}^{3,4}$ \\ ${ }^{1}$ Department of Educational Studies, Ghent University, Ghent, Belgium \\ ${ }^{2}$ Institute of Education, National Sun Yat-sen University, Kaohsiung, Taiwan \\ ${ }^{3}$ Interculturalism, Migration and Minorites Research Center, KU Leuven, Leuven, Belgium \\ ${ }^{4}$ Institute of Political Sciences, National Sun Yat-sen University, Taiwan \\ Correspondence: Hsien-Ming Lin. Tel: 32-487-38-0158. E-mail: hsienming79@gmail.com
}

Received: July 17, $2018 \quad$ Accepted: July 23, $2018 \quad$ Online Published: September 28, 2018

doi:10.5539/ass.v14n10p75

URL: https://doi.org/10.5539/ass.v14n10p75

\begin{abstract}
In 2017, Taiwanese government started to implement New Southbound Policy. For this policy, strengthening the cultivation and exchange of skilled people, or "talent," between Taiwan and the southbound countries (NSPC) is the most important purpose. Notably, current data revealed that students of NSPC are more likely to study abroad in Taiwan; moreover, previous studies have explored this phenomenon called as 'Global South to Global North', which means the experiences of students from developing countries studying in developed countries. However, compared to students of NSPC, the number of Taiwanese students studying abroad in NSPC is relatively less. To our understanding, no studies have explored what the causes for the above are. Therefore, this is a pioneer study to explore the perspectives of the students from developed countries toward studying abroad in developing countries, so that we can understand what are the main factors which may be considered when Taiwanese students consider studying abroad to NSPC (except for Singapore, Australia, and New Zealand). The mixed methods design was adopted in this study. 147 Taiwanese students accepted the questionnaire survey, 8 Taiwanese students were interviewed. The results indicated that, the following three factors are mainly taken into consideration by Taiwanese students when considering studying abroad to NSPC: academic, economic, and personal factor. Moreover, the results also echoed with the perspective of rational choice theory, which means the above three factors will be considered by students rationally, thereby influencing their decision-making on studying abroad. Furthermore, three suggestions were proposed for promoting Taiwanese students to study abroad in new southbound countries: first, Taiwanese government could assist public to broaden their understanding of these countries; second, Taiwanese government could provide students more necessary information such as the prominent academic subjects and its development in these countries, thereby helping them make decision on studying abroad in NSPC. Third, Taiwanese government could create more working opportunities for these Taiwanese students who graduate from NSPC.
\end{abstract}

Keywords: new southbound policy, choice factor, Taiwanese students, study abroad

\section{Introduction}

\subsection{The Ideas and Goals of the New Southbound Policy in Taiwan}

After Taiwan's new president (i.e. Tsai Ing-wen) took power in May 2008, she announced an important new regional strategic policy called the New Southbound Policy (NSP). The policy targets 18 countries, including the 10 Association of Southeast Asia Nations (ASEAN) member countries, six south-Asian countries, Australia, and New Zealand. In the past, the southbound policy focused on promoting and facilitating economic and trade relationships between Taiwan and these countries, which meant the Taiwanese government provided significant development assistance to many of them as part of this policy. However, this time, the core concept of the NSP is that it is "People-Oriented," which means that it not only concerns trade and economic issues, but also emphasizes interaction and cooperation in areas such as economy, industry, talent exchange, technology, etc. Therefore, it is apparent that the Tsai Ing-wen administration is moving toward a focus on collaboration rather than aid and attaching greater importance to establishing "a sense of community" between Taiwan and these southbound countries by creating mutual benefit and mutual growth (Yang, 2017). 
Because the (NSP) is based on the People-Oriented perspective, strengthening the cultivation and exchange of skilled people, or "talent," between Taiwan and the southbound countries is the most important purpose of this policy for relevant government departments. In this regard, Taiwan's Ministry of Education developed a three-year program (2017-2020) for "Talent Cultivation between Taiwan and New Southbound Policy Countries" (NSPC) based on the NSP guidelines and promotion program. The program emphasizes that Taiwan's government will not only provide more grants and scholarships to the students of NSPC who are willing to study in Taiwan (i.e. the attracting strategy), but will also provide such financial aid to Taiwanese students who want to go to other NSPC countries for education, internships, etc. (i.e. the go out strategy). By doing so, Taiwan's government hopes to promote Taiwanese universities and colleges, to create more educational exchange opportunities for those in NSPC, and to deepen interactions and relations between Taiwan and the southbound countries. Thus, this deepened commitment to fostering educational exchange will help fulfill the NSP vision for the promotion of economic development through cooperation and educational exchange. Specifically, through the implementation of this program, the Taiwanese government expects that the number of students in Taiwan from NSPC will grow 20\% per year from 2017 to 2020 so that by 2020, the total number of students from NSPC will be 58,000, while the number of Taiwanese students who study or intern in NSPC countries will be 3280 (Yang, 2017).

\subsection{The Number of Taiwanese Students Who Study in NSPC and the Number of NSPC Students Who Study in Taiwan}

The problem of facilitating opportunities for student interaction has become a crucial part of implementing the policy. The following data provides some evidence to evaluate the effectiveness of the "attracting policy." As shown in Table 1, from 2007 to 2015 the number of degree- oriented students from the NSPC rose from 8,760 to 19,747 , an increase of $125.42 \%$. The number of NSPC students increased further in 2016, to 21,882 . Degree-oriented students from the NSPC accounted for $42.29 \%$ of the total number of foreign degree-oriented students in Taiwan, making NSPC the most significant source of foreign students in Taiwan. Notably, among the 18 NSPC, most students come from Malaysia, followed by Indonesia, India, Thailand, and Myanmar. The study conducted by Lin (in press) demonstrated that the reference groups have the most powerful influence on the students from Malaysia and Indonesia for deciding to study in Taiwan. Lin found that a large number of overseas Chinese and foreign students from Malaysia have studied in Taiwan for a long time, which has resulted in an abundance of interpersonal alumni networks in Malaysia. These alumni networks have played a crucial role in helping other students determine whether they want to study in Taiwan or not. "The Federation of Alumni Associations of Taiwan Universities, Malaysia," established in 1974, has been in existence for more than 40 years. Every year, this alumni group not only organizes an educational fair to introduce the students to study in Taiwan but also publishes a guide for the students know more about some information about studying in Taiwan. Additionally, the association has helped students buy cheaper flight tickets by negotiating with the airlines. The goals of this association not only bind the alumni together but also encourage more Malaysian students to study in Taiwan, and even the association also emphasizes on facilitating mutual interaction between the universities and the governments of Malaysia and Taiwan. According to statistical data from the association, in 2003 there were 2000 teachers in the overseas Chinese private senior high school in Malaysia, and more than half of these teachers earned their degrees in Taiwan. The alumni networks and associations have played a critical part in helping students decide to study in Taiwan (James-Maceachern \& Yun, 2017). Moreover, the most popular disciplines for the degree-oriented students from the NSPC are business and management, engineering, humanities, and communications studies, while the least popular includes environment, transportation, social services, law, and mathematics (Ministry of Education, 2017).

Table 1. The number of the Degree-Oriented Students from New southbound countries in Taiwan

\begin{tabular}{cccccccccc}
\hline Country/Year & 2015 & 2014 & 2013 & 2012 & 2011 & 2010 & 2009 & 2008 & 2007 \\
\hline Malaysia & 11,534 & 9,925 & 8,141 & 6,927 & 6,039 & 5,444 & 4,828 & 4,106 & 3,775 \\
Vietnam & 2,895 & 2,741 & 2,568 & 2,535 & 2,244 & 3,442 & 1,623 & 1,169 & 873 \\
Indonesia & 2,725 & 2,345 & 2,043 & 1,855 & 1,677 & 2,301 & 1,392 & 1,353 & 1,287 \\
Thailand & 768 & 816 & 799 & 725 & 718 & 680 & 659 & 638 & 571 \\
Myanmar & 467 & 412 & 407 & 433 & 558 & 726 & 994 & 1,229 & 1,582 \\
Singapore & 190 & 199 & 181 & 179 & 158 & 136 & 117 & 84 & 75 \\
\hline
\end{tabular}




\begin{tabular}{cccccccccc}
\hline Philippines & 174 & 171 & 190 & 178 & 159 & 172 & 200 & 193 & 144 \\
Brunei & 18 & 16 & 13 & 14 & 11 & 8 & 6 & 7 & 6 \\
Cambodia & 3 & 2 & 2 & 6 & 7 & 6 & 11 & 17 & 28 \\
Laos & 4 & 4 & 4 & 2 & 1 & - & - & - & - \\
India & 804 & 649 & 496 & 439 & 388 & 368 & 342 & 323 & 309 \\
Nepal & 34 & 29 & 28 & 21 & 16 & 18 & 16 & 15 & 11 \\
Pakistan & 36 & 21 & 14 & 8 & 3 & 3 & 2 & 2 & 2 \\
Sri Lanka & 17 & 15 & 15 & 13 & 5 & 8 & 7 & 5 & 4 \\
Bengal & 15 & 13 & 20 & 22 & 22 & 17 & 16 & 14 & 11 \\
Bhutan & 1 & 1 & 1 & - & - & - & - & - & - \\
Australia & 31 & 35 & 27 & 38 & 36 & 39 & 47 & 49 & 45 \\
New Zealand & 31 & 34 & 34 & 35 & 30 & 29 & 34 & 35 & 37 \\
Total & 19,747 & 17,428 & 14,983 & 13,430 & 12,072 & 13,397 & 10,294 & 9,239 & 8,760 \\
\hline
\end{tabular}

Table 2 is regarding the non-degree-oriented students. The number of NSPC students who study in Taiwan increased from 4,195 in 2007 to 9,649 in 2016, an increase of 130\%. In 2016, most non-degree-oriented students came from Malaysia, which accounts for $35 \%$ of the total number of non-degree-oriented students from NSPC. Malaysia is followed by Indonesia, Vietnam, Thailand, and Singapore. Of the non-degree students who came from south-Asian countries in the NSP, the biggest proportion were from India. The number of students from Australia exceeded that from New Zealand.

To sum up, the majority of students who come from NSPC are doing so with the purpose of earning a degree from Taiwanese universities or colleges. However, the number of both degree-oriented and non-degree-oriented students has grown rapidly in the past ten years. It seems that the "attracting strategy" has had an impact.

Table 2. The number of the Non-Degree-Oriented Students from New southbound countries in Taiwan

\begin{tabular}{ccccccccccc}
\hline Country/Year & 2007 & 2008 & 2009 & 2010 & 2011 & 2012 & 2013 & 2014 & 2015 & 2016 \\
\hline Malaysia & 223 & 173 & 430 & 417 & 2196 & 2563 & 3224 & 3361 & 3412 & 3362 \\
Vietnam & 634 & 739 & 1161 & 1917 & 1668 & 1383 & 1065 & 974 & 1148 & 1609 \\
Indonesia & 1243 & 1537 & 901 & 1487 & 898 & 1048 & 1143 & 1214 & 1669 & 1943 \\
Thailand & 364 & 413 & 509 & 532 & 586 & 721 & 747 & 719 & 713 & 965 \\
Myanmar & 30 & 6 & 7 & 4 & 7 & 23 & 33 & 76 & 112 & 78 \\
Singapore & 83 & 118 & 123 & 159 & 196 & 242 & 425 & 479 & 557 & 434 \\
Philippines & 144 & 169 & 185 & 211 & 314 & 317 & 336 & 395 & 359 & 446 \\
Brunei & 1 & 1 & 0 & 1 & 6 & 6 & 12 & 7 & 7 & 15 \\
Cambodia & 8 & 7 & 3 & 0 & 2 & 0 & 2 & 2 & 1 & 2 \\
Laos & 0 & 0 & 0 & 3 & 1 & 1 & 0 & 1 & 0 & 1 \\
India & 106 & 85 & 96 & 109 & 157 & 149 & 149 & 208 & 339 & 377 \\
Nepal & 7 & 6 & 5 & 7 & 14 & 14 & 9 & 24 & 20 & 14 \\
Pakistan & 1 & 1 & 0 & 5 & 3 & 4 & 3 & 2 & 3 & 9 \\
Sri Lanka & 2 & 1 & 1 & 3 & 4 & 5 & 3 & 1 & 1 & 4 \\
Bengal & 0 & 0 & 1 & 4 & 4 & 3 & 2 & 3 & 0 & 1 \\
Bhutan & 5 & 4 & 0 & 2 & 0 & 2 & 5 & 11 & 14 & 8 \\
Australia & 162 & 158 & 212 & 231 & 219 & 233 & 286 & 336 & 376 & 305 \\
New Zealand & 92 & 69 & 40 & 59 & 75 & 63 & 67 & 48 & 72 & 76 \\
Total & 4195 & 3487 & 3674 & 5151 & 6350 & 6777 & 7511 & 7861 & 8803 & 9649 \\
\hline
\end{tabular}


Compared to the "attracting strategy," the effects of the "go out" policy have been limited. The following table (Table 3) shows the number of Taiwanese students who learn and intern in the NSPC. From 2014 to 2016, the number of Taiwanese students in the NSPC decreased from 658 to 179, its lowest point and a decrease of $267 \%$. Moreover, the number of degree-oriented Taiwanese students in NSPC also decreased, by 33\%, from 241 in 2013 to 161 in 2016. To sum up, the number of Taiwanese students who study in NSPC is much lower than the number of NSPC who study in Taiwan. This raises the question: What factors do Taiwanese students consider when making the decision to study abroad?

Table 3. The number of the Taiwanese students for interning and learning in new southbound countries

\begin{tabular}{cccc}
\hline Country/Year & 2015 & 2014 & 2013 \\
\hline Malaysia & 69 & 95 & 17 \\
Vietnam & 90 & 81 & 14 \\
Indonesia & 31 & 30 & 20 \\
Thailand & 102 & 152 & 68 \\
Myanmar & 0 & 0 & 0 \\
Singapore & 238 & 290 & 47 \\
Philippines & 0 & 17 & 3 \\
Brunei & 0 & 9 & 1 \\
Cambodia & 0 & 0 & 0 \\
Laos & 0 & 0 & 0 \\
India & 530 & 674 & 170 \\
Nepal & 0 & 6 & 0 \\
Pakistan & 10 & 0 & 0 \\
Sri Lanka & 0 & 0 & 0 \\
Bengal & 0 & 0 & 0 \\
Bhutan & 0 & 0 & 0 \\
Australia & 0 & 0 & 0 \\
New Zealand & 10 & 6 & 0 \\
Total & 96 & 53 & 9 \\
\hline
\end{tabular}

\subsection{Choice Factors in the Study Abroad Decision}

There are two theories, push-pull theory and rational choice theory, which can provide explanations for students' decisions to study abroad, and therefore shed some light on what factors might be important to consider in order to understand their decision-making process.

Push-Pull theory offers a macro perspective, and takes into consideration political, economic, educational, social and cultural factors to explain students' study abroad decisions. These factors can be divided among two categories: push factors related to the home country which encourage students to leave for study abroad, and pull factors related to host country which attract students to study abroad there. Chang and Yu (1999) examined both push and pull factors. Factors related to the home country which promote study abroad include economic factors such as whether the host country has a higher GNP than the home country, and the exchange rate between two countries. Educational factors relate to whether the host country offers generous scholarships or grants and easy access to enrollment as well as a similar educational system to the home country). Political factors include the colonial and/or diplomatic relationship between the two countries. Finally, social and cultural factors pertain to whether the two countries share a similar or the same culture or language. The factors related to the host country's attraction for students include educations factors such as friendly policies and attitudes toward applications, scholarships and grants, the learning environment, and language enhancement., Environmental factors such as transportation, safety, living environment and the convenience of host country also play a role, as do, political factors such as political stability and diplomatic relations between the two countries. Historical and cultural factors relate to whether the host country shares a similar culture with the home country. According to 
the Push-Pull theory, students' choice about where to study is influenced by all of these "push" and "pull" factors discussed above, and often their decision is made by maximizing utility.

The macro perspective of Push-Pull theory is one perspective that has guided previous research, and emphasizes the role of macro factors - political, educational, economic, and social/cultural - in shaping students' study abroad choices. Rational choice theory focuses on a micro, or individual perspective. It argues that individual decisions about studying abroad are driven by rational consideration and judgment. The factors affecting an individual's decision are not only those related to the macro perspective as discussed above, but also those related to the micro perspective such as students' personality traits, capabilities, motives, goals, and gender (Li \& Bray, 2007). Students who are extroverted and enjoy adventures and challenges, for example, are more likely to choose to study abroad (Chen, 2006). The decision to stud abroad is also related to individual goals, such as achieving class mobility (Eccles \& Wigfield, 2002; Wigfield \& Eccles, 2000). In addition, an individual's decision will also be affected by personal preferences, such as those for a host country's climate and living environment, for example (Altbach \& Knight, 2007). According to rational choice theory, individuals take all of the factors mentioned above into consideration when choosing to study abroad. Moreover, the human capital theory, another theory focusing on micro perspective, can be used to explain how students choose the host countries for studying abroad. According to the definition provided by OECD, human capital means "the knowledge, skills, competencies and other attributes embodied in individuals or groups of individuals acquired during their life and used to produce goods, services or ideas in market circumstances" (OECD, 2007). In this regard, people view studying aboard as an investment for individual's human capital. However, Nguyen (2017) argued that people may be influenced by the interaction experience with others and the socio-political discourses in the society in shaping their decisions to invest in education, as well as choices of the destination for studying, which means that peoples' decisions in education and international study are not the objective consideration; instead, it would be the subjective decision which is influenced by different interaction experiences and relevant factors combining with the macro socio-political and micro individual issues.

Accordingly, this study combined the above theories and concepts from macro and micro systems and divided students' studying abroad choice factors into six categories. Academic factors include the academic aspects of universities and colleges in host countries such as academic reputation, sufficiency of resources, faculty structure, learning environment, difficulty of admission, and complexity of application procedure. Cultural factors include the host country's language and habits and customs. Political factors include the tenor of diplomatic relations between the host country and the home country. Economic factors relate to the relevant economic aspects of host countries such as university tuition and fees, cost of living, scholarship and grant opportunities, local social welfare support, and residency and employment opportunities. Social factors include the living quality, safety, geographic location, climate, and networks of friends or relatives already living or studying in the host country. Finally, personal factors are those that pertain to individual goals such as the potential for study abroad to advance one's career development, broaden one's horizon or add to one's personal experience in a meaningful way (Ma, 2000; Knight, 2006; Szelényi, 2006).

\subsection{Review of Literature on Choice Factors and the Study Abroad Experience}

We now explore some empirical studies regarding students' choice factors and study abroad experiences. It is worth noting that most relevant studies focus on the study abroad experience from "Global South to Global North," which means the main focus of the existing literature is on the experience of students from developing countries studying in developed countries. There are fewer relevant studies exploring the motivations of students from developed countries who study abroad in developing countries (MacGregor, 2016).

Only a few studies have focused on both the study abroad experiences and choice factors of Taiwanese students who study abroad in developing countries. The study conducted by Wu and Lan (2012) focusing on Taiwanese students who study abroad in China, identified three types of motivations for studying in China. First, degree-oriented study abroad is motivated simply by the expectation of earning a degree, or acquiring human capital. However, these students have no plan to work in China after graduation. Work-oriented study abroad is motivated by the expectation of staying in China to work after graduation. Moreover, these students expect to gain social and cultural capital through their study abroad experience, thereby increasing their competitiveness in the Chinese labor market. Family-oriented study abroad is motivated by the decision of parents or families instead of that of the student herself. Lin (2012) found that students engaged in family-oriented study abroad expected to obtain more opportunities to upgrade their social status by studying abroad in China.

\subsection{The Present Study}

While these studies provide insight into Taiwanese students' experiences studying abroad in China, this appears 
to be the extent of the studies of Taiwanese students studying abroad in developing countries. To our knowledge, no studies have explored the study abroad experience and choice factors for Taiwanese students in developing countries other than China

Given the Taiwanese government's NSP, and the fact that in spite of this, the number of Taiwanese students who study abroad in NSPC remains quite low, this study aims to adopt mixed-method (i.e. a combination of questionnaire survey and interview) to explore the attitudes of Taiwanese students toward studying abroad in NSPC, as well as the main factors students consider in making their choices to study abroad in these countries. Based on the aforementioned theories and the results of relevant studies, we expect that there will be multiple factors considered by students for rationally making their choices to study abroad in NSPC, rather than one factor merely. We expect that the results of this study can be added to the relevant literature of both theoretical and empirical studies regarding the choice to study abroad from developed countries to developing countries, not only by showing the concrete choice factors in students' decision to study abroad in NSPC or not, but also by clarifying the complex, dynamic process behind their decision making.

\section{Methods}

\subsection{Participants}

Participants were recruited for this study via convenience sampling and purposive sampling. To be eligible to participate, individuals had to be Taiwanese students who are studying in either Taiwanese colleges or universities (i.e. bachelor students, master students, doctoral students). The concurrent embedded design, proposed by Cresswell and Clark (2007), was the type of mixed methods design, adopted in this study. The qualitative data gathered can be used to explore the meaning behind the quantitative data, thereby adding benefit of overcoming problems of insufficient quantitative data (Sung \& Pen, 2010). Therefore, the participants in study were divided into both quantitative and qualitative samples.

For the quantitative data, a total of 147 Taiwanese students participated in the survey and filled out an online questionnaire regarding the attitudes and choice factors of Taiwanese students toward studying abroad in NSPC. Of these questionnaires, 143 were valid and complete. In the sample of 143 , there were 54 males and 89 females. There were 79 bachelor's students, 55 master's students, and 9 doctoral students. The age range was 18 to 55 , and the average age was 24.07.

For the qualitative data, a total of 8 Taiwanese students were recruited and interviewed. Eleven interview transcripts were developed because 3 students were interviewed twice. Of these, 3 were males, and 5 were females, with 2 bachelor's students, 4 master's students, and 2 doctoral students. The age range was 27 to 32 . The mean age was 28.75. 5 were from Northern, and 3 from Southern Taiwan.

\subsection{Instrument}

\subsubsection{Online Questionnaire}

The online questionnaire used in this study was developed with reference to questionnaires related to considering factors of studying abroad (Chen, 2011; Ma, 2014). After its initial development, two experts specializing in the study abroad research and psychometrics, as well as two Taiwanese students were invited to review and revise the survey and to confirm that the relevant choice factors regarding studying abroad were included. In this way, the validity of the questionnaire was confirmed.

The questionnaire is divided into three parts. The first part consists of one item for exploring students' willingness to study abroad in NSPC. It is scored on a 10-point Likert scale ranging from not willing (0) to very willing (9).

The second part consists of 23 items (i.e. 1 global item and 22 specific items) for exploring students' choice factors for studying abroad in NSPC. The global item is aimed to understand what factors are high priorities for students considering studying abroad in NSPC. The specific items explore the importance of different sub-factors of each of the five main factors: academic, cultural, political, economic, and personal. Like the first item, these are scored on a 10-point Likert Scales ranging from not willing (0) to very willing (9). Academic factors (5 items) include academic aspects of universities and colleges in NSPC such as academic reputation, sufficiency of resources, faculty structure, learning environment, etc. Cultural factors (3 items) include such aspects as language, habits and customs, life styles, etc. Political factors (1 items) include the tenor of relations between Taiwan and NSPC. Economic factors (6 items) refer to aspects as tuition and fees, cost of living, scholarship and grant opportunities, local social welfare supports, residency and employment opportunities, etc. Social factors (5 items) refer to things like living quality and function, safety, geographical location and climate, having friends or relatives who live or study in NSPC, etc. Finally, personal factors ( 2 items) refer to the extent 
to which the study abroad experience promotes students' career development, broadens horizons, or constitutes a meaningful life experience.

The third part consists of an open question for collecting students' feedback or suggestions regarding the NSP.

The second part constitutes the main part of the questionnaire; therefore, a Rasch partial credit model (PCM) and ConQuest 2.0 software were adopted to assess the psychometric quality of this part in this study. The Rasch technique is appropriate because it can provide indices to assess an item's fit (Bond \& Fox 2016). The results of the analysis of unidimensional Rasch PCM model showed that the infit MNSQ (mean square) indices for all items under these six main categories ranged from 0.67 to 1.40, which met the criterion set by Bond and Fox (2007), (i.e. 0.6 to 1.4). This means that the items, or sub-factors, included in the same factor category all measure the same construct. Second, the results of the analysis of multidimensional Rasch PCM model revealed that the infit MNSQ (mean square) indices for all items ranged from 0.60 to 1.39, which also met the criterion set by Bond and Fox (2007). This means the choice factors can be divided into these six categories. Moreover, the item separation reliability of the 22 items, or sub-factors, is 0.96 , which means the logit value of these items can be effectively differentiated in terms of this sample (Linacre, 2006). To sum up, the second part of this questionnaire possessed positive reliability and validity.

\subsubsection{Interview Outline}

This study employed semi-structured interviews to collect qualitative data. This interview outline was based on the results from the quantitative data, and was aimed to further clarify the students' choice factors in studying abroad in NSPC.

First, we asked participants, "If you want to study abroad, will NSPC be your priority? Why or why not? Second, we shared with participants the results of the quantitative analysis, that what main factors are taken into consideration by Taiwanese students when they consider whether to study abroad in NSPC. We then asked participants the following questions:

1. In terms of the above factors, what factor(s) might motivate (or deter) you to study abroad in NSPC? Why?

2. Except for the above factors, would anything else have an impact on your willingness to study abroad in NSPC? Why?

3. Could you share with me your perspectives toward the new southbound policy? Do you have any suggestions for improving this policy?

\subsection{Procedures and Data Analysis}

\subsubsection{Participants' Invitation for the Quantitative Part of This Study}

Firstly, we posted relevant research information (e.g., the purposes, contents, rights of participants, and the website address of the questionnaire, etc.) to social websites (e.g., Facebook, BBS, etc.) and posted an invitation to potential participants to fill out the questionnaire. And then, we also asked them to promote this research to others.

\subsubsection{Quantitative Data Analysis}

After inputting these collected quantitative data in text form, we began analysis. For the first part of the questionnaire, we used SPSS 21.0 to calculate the median value of the Taiwanese students' willingness to study abroad in NSPC via SPSS 21.0.

For the second part of the questionnaire, we counted the number of times each factor was chosen by participants. We then used SPSS 21.0 to perform a Chi-square goodness-of-fit test to clarify the most important category of choice factors for Taiwanese students in deciding to study abroad in NSPC.

After confirming what the most important choice factors are, we conducted further analysis to clarify the important sub-factors (e.g., faculty structure, curriculum, etc.) under these main categories (e.g., academic factors). For this, we adopted a Rasch PCM model to calculate the item difficulty values and the importance of these sub-factors. This study regarded the seventh Thurstone threshold of each of the items, or sub-factors, as the cutoff point to judge whether participants considered a particular sub-factor to be important.

\subsubsection{Participants' Invitation for the Qualitative Part of This Study}

After completing the analysis of the quantitative data, we adopted purposive sampling to extend invitations to potential participants in the interviews to further clarify the Taiwanese students' perspectives toward studying abroad in NSPC. First, we used part of the Delphi technique (Okoli \& Pawlowski, 2004) to set up a nominating 
panel with which we identified and nominated potential research participants, or the ones who expressed a higher willingness to study abroad and to share their experience. After completing the nomination process, we contacted these potential participants by phone, explained the research information to them, and confirmed whether they were willing to participate in this study.

\subsubsection{Formal Interviews}

Before conducting the formal interviews with these participants, we reminded them about the interview procedure and their rights in this study. We also requested permission to record the interviews using pen recorders. A total of 8 Taiwanese students participated in these interviews. The duration of each interviews ranged from 60 to 90 minutes, with a mean duration of 68 minutes per interview.

\subsection{Qualitative Data Analysis}

\subsubsection{Data Analysis}

We transcribed the audio data and the third part of the questionnaire into verbatim transcripts. All verbatim transcripts were coded by two coders. They discussed the codes and concepts at regular intervals (Silverman, 2015). The intercoder reliability of this study was 0.88 , which means it is positive for coding consistency (Sim \& Wright, 2005).

The qualitative data analysis method introduced by Wolcott (2008) was adopted in this study. First, we focused on reading the interview transcripts in order to thoroughly understanding their meaning and content. Second, we coded the important concepts in these transcripts, such as poor academic quality and insufficient resources. Third, we compared the data with these concepts, and classified the important concepts into categories. For instance, the concepts were classified into the category 'academic factor'; Fourth, the relationships among categories were established. Eventually, the researchers developed the conceptual framework to obtain deeper understanding toward the phenomenon. For example, the structure of considering factor was established, which meant three factors, such as academic factor, economic factor, and personal factor were included in.

\subsubsection{The Quality of Analysis}

We adopted relevant approaches for ensuring the quality of the study in terms of its credibility, transferability, dependability, and confirmability, thereby enhancing the trustworthiness of the qualitative research (Merriam, 2002).

Credibility. We respected all perspectives and responses of the participants to make them feel comfortable and more willing to share their experiences during the interview process. Moreover, we discussed the results of the analysis with colleagues at regular intervals to increase our understanding of what participants were expressing.

Transferability. We depicted the results of this study as clearly as possible and appropriately quoted participants' interview excerpts.

Dependability. To collect dependable data, we recorded the interviews and then compared them with the verbatim transcripts to ensure that the transcripts were accurate before they were analyzed. Furthermore, we attached importance to the Audit trail, which means that the research methods, procedures, and processes of data analysis were clearly described in this study, thereby making the results transparent.

Confirmability. To ensure the confirmability of the results and to avoid any bias, the researchers adopted the following three techniques in this study: reflectivity, peer debriefing, and member checks. Reflectivity makes us aware any potential bias in the study. Peer debriefing exerts the peer-check effect by discussing the results of the analysis with colleagues. Member checks confirm whether the participants' perspectives could be fully represented by sending the initial analytic results to them.

\section{Results}

\subsection{Quantitative Data}

Quantitative data analysis is divided into three parts. First, this study analyzed Taiwanese students' willingness to study abroad in NSPC. Second, we explored the important choice factors in the study abroad decision. Finally, we broke down the main factor categories into sub-factors, and explored the importance of these.

\subsubsection{Analysis of the Willingness to Study Abroad in NSPC}

Descriptive statistical analysis indicated that the median of participants' willingness to study abroad in NSPC is 4, and the mean is 4.5. As 10 indicated the highest level of willingness, this indicates that Taiwanese students' willingness to study abroad in these countries is not high. 


\subsubsection{Analysis of the Main Choice Factors}

The analysis of the results of the chi-square goodness-of-fit test indicates that there are significant differences in the importance of the main choice factors, with $\chi^{2}=92.93, p<.001$. Comparing the actual with expected numbers of these factors, we find that the most importance main factor category is that of academic factors, followed by the categories of economic factors and personal factors (Table 4).

Table 4. Main choice factors for considering studying abroad in NSPC

\begin{tabular}{ccc}
\hline Factors & Actual numbers & Expected numbers \\
\hline Academic factors & 49 & \\
Culture factors & 9 & 23.8 \\
Political factors & 4 & \\
Economic factors & 40 & \\
Social factors & 2 & \\
Personal factors & 39 & \\
\hline
\end{tabular}

\subsubsection{Analysis of the Choice Sub-factors}

As indicated above, the three main categories of factors that Taiwanese students consider when deciding whether to study abroad in NSPC are academic, economic, and personal. We further analyzed the importance of the sub-factors of these main categories.

After analysis, we found that the distribution of importance levels of the academic factors $(M=1.50, S D=.70)$ appears to be broader than the distribution of the item difficulties $(M=0, S D=.13)$, which means the academic factors is important to the participants. In this figure, the most important sub-factor (i.e. the lowest difficult item) is the programs in universities and colleges of NSPC (-.16 logits). The second to the fifth are the international and global extent of universities and colleges in NSPC (-.09 logits); the faculty structure of universities and colleges in NSPC (-.07 logits)"; the teaching equipment and learning environment of universities and colleges in NSPC (.03 logits); and the reputation of universities and colleges in NSPC (0.29 logits).

Moreover, the distribution of importance levels of economic factors $(M=.72, S D=.49)$ is broader than the distribution of the item difficulties $(M=0, S D=.23)$, which means the economic factors is also important to the participants. Among these sub-factors, we find that the most important sub-factor is whether Taiwan's government provides enough opportunities for scholarships for the students who want to study abroad in NSPC (-.42 logits). The second one is the tuition and fees of universities and colleges in NSPC (-.21 logits). The third one is the social security provided by NSPC's governments for the students who want to study abroad in NSPC (-.05 logits). The fourth one is the possibility of living and working in NSPC after graduation (-.05 logits). The fifth one is whether NSPC's governments provide enough opportunities for scholarships for the students who want to study abroad in NSPC (.26 logits). The last one is the extent of cost of living in NSPC (0.47 logits).

Furthermore, the distribution of importance levels of personal factors $(M=.76, S D=.45)$ is also broader than the distribution of the item difficulties $(M=0, S D=.34)$, which means the personal factors is important to the participants. Notably, the most important sub-factor is whether one's self-vision and experiences can be expanded by studying abroad in NSPC (-.19 logits). The second most important sub-factor is the contribution of the study abroad experience for my future career development (e.g., pursuing higher education and employment) (.19 logits).

In conclusion, the main category of academic factors is the most important choice factor for Taiwanese students when considering whether to study abroad in NSPC, followed by economics, then personal factors.

\subsection{Qualitative Data}

The qualitative results were drawn from interview data and an open question on the online questionnaire. It conformed with the above quantitative analysis results, thereby clearly showing the choice factors and attitudes of Taiwanese students toward studying abroad in NSPC. Three important choice factors are discussed.

\subsubsection{Academic Factors}

Most students considered the category of academic factors as the most important when deciding whether to study abroad in NSPC. For these students, they thought that, except for universities and colleges in some NSPC such 
as Singapore, Australia, and New Zealand, the academic performance and resource investment of universities and colleges in most NSPC are generally not high in comparison to ones in the United States and European countries. For students whose goal of studying abroad is obtaining more opportunities to obtain a higher degree (e.g., doctoral degree) in the future, the academic reputation of universities and colleges in NSPC is of the utmost importance. They generally think that studying abroad in NSPC is not helpful for them to successfully apply for higher degrees in other countries. This is one of the reasons they are not willing to study abroad in NSPC. As Student D-072 expressed,

If I want to earn a master degree or doctoral degree by studying abroad, I will be less likely to earn the degree from these NSPC. This is because the academic reputations of universities in these countries are not well in comparison to the ones in America and European countries. If I can earn my master degree in America or European countries, this will be helpful for me to apply for doctoral admission in other prominent universities around the world. Honestly, it is a practical consideration, and I have to make an appropriate plan for my future (sic).

If the programs offered by universities and colleges of NSPC were more attractive to Taiwanese students, they would be more likely to study abroad there. Appealing programs include programs that are unique to these countries, programs which attract close government attention in these countries, and programs that can provide additional language learning opportunities such as in English or local languages. As the following students said:

If I have to study abroad in NSPC under the circumstance of excluding some countries (i.e. Singapore, Australia, and New Zealand), the academic reputation of universities and colleges in these countries may not be the most important considering factor to me. Instead, I think something really attracts me is whether there are some featured programs in these countries. For example, the development of the audio-visual industry in Thailand is quite well. I think they successfully make their own style in the development of this industry, especially for creative advertisements. Therefore, the departments related to the audio-visual industry in Thailand are appealing for me, such as department of advertising or department of mass communication ( sic). (F-077)

English education is great in the Philippines. For example, their textbooks are written by English. What the feature attracts me to study in NSPC is language. I will search for the programs with additional language learning opportunity there. This is because you not only can accumulate professional knowledge by these programs but also practice English in these programs (sic). (C-059)

Although I am unfamiliar with local languages of NSPC, I still believe that it will be an incentive for me to study abroad there if some courses with local languages can be provided there. After all, the talents related to these kinds of languages are still lacking in Taiwan such as Vietnamese, Phasa Thai, Bahasa Indonesia, etc. Moreover, one important academic factor to me is whether there is any appropriate English graduate program for me? Most Taiwanese students are not good at the local languages in these countries. I think English should be adopted in the process of learning, especially for the majors that we want to cultivate. After all, our abilities of local languages are not good enough to be used for learning these majors there (sic). (E-086)

Moreover, some participants also stated that they would attach importance to the level of internationalization of universities in NSPC because they expected to obtain more educational or internship opportunities in universities or institutions in other countries (e.g., countries around the world or in the new southbound area). In this way, they hoped that studying abroad would help them to broaden their horizons and accumulate relevant experience. As Student C-024 mentioned:

If a university can make collaboration with other universities around the world, this means that the internationalization level of this university is high that may be beneficial for me to study in there. You know...this collaboration means they have more resource exchange with other universities around the world (sic).

To sum up, it is worth noting that many students have limited understanding of the academic aspects of universities or colleges in NSPC, such as their prominent majors and features. Therefore, they merely rely on their stereotypes to evaluate the academic performance of these universities or colleges. This may eliminate their willingness to study abroad in these countries.

\subsubsection{Economic Factors}

When it comes to economic factor, most students considered that, two sub-factors, whether enough opportunities of scholarship application can be provided and whether the tuition fee of universities or colleges in NSPC is 
cheap, will be taking into consideration when considering whether to study abroad in NSPC. Firstly, they thought that, under the circumstance of promotion of new southbound policy, the Taiwanese students, who want to study abroad in NSPC, are more likely to obtain more opportunities of scholarship application not only from Taiwanese government but also from some non-governmental institutions. This will enhance Taiwanese students' willingness toward studying abroad in NSPC. As a student A-066 mentioned that: "Obtaining enough grants means that you do not have to worry about any problem related to money, instead, you can concentrate on your learning in there." Moreover, most students have limited understanding of the local education system of these countries and relevant information cannot be found on internet easily, so they have no idea whether the tuition fee of universities or colleges in these countries will be the heavy burden to them. Therefore, they took this sub-factor into consideration. However, based on their impressions to NSPC, they generally thought that, tuition fee of universities or colleges in these countries may be cheaper than other countries such as England and the united stated, which are the preference of Taiwanese students. Hence, this sub-factor is appealing to them when considering whether to study abroad in these countries. As two students F-114 and D-048 both pointed out that:

I think the tuition fee will be the important considering factor. However, I think these NSPC have great competitiveness as to this factor. You know...compared to the expensive tuition fee in England or America, I believe that the tuition fee in NSPC is not more expensive than ones in America and England. For instance, Vietnamese government developed a free graduate program before, right? This is really an incentive to me (sic). $(F-114)$

The economic factor is important to me. Except for some countries such as Singapore, Australia, and New Zealand, the tuition fee and cost of living in remaining NSPC are cheaper than ones in the united stated and European countries. It means that I not only can spend less money on studying abroad but also earn a degree (sic)! (D-048)

It is worth noting that, some students also mentioned if governments of NSPC can make a guarantee that international students who graduated from local universities in NSPC have more opportunities of working in these countries, this may be the important considering sub-factor for them to study abroad in these countries. Especially, this sub-factor is more important to the students who want to search for jobs after graduation. Moreover, they emphasized that, if both salary and future development of these employments could be better than ones in Taiwan, this will enhance their willingness regarding studying abroad in these countries more. However, if there is no any guarantee for job opportunities, it may have impact on their willingness toward studying abroad in these countries. As two students D-033 and A-035 mentioned that:

If I can find a job there successfully after my graduation, it will be the important factor for me to study abroad there. Especially, if its salary is twice than the one in Taiwan, I definitely will study abroad there. I remember an experience that, I was an international volunteer in a Malaysian elementary school two years ago. At that time, I taught the guidance curriculum there. After finishing my instruction, the school principal came to me and asked me that whether I am willing to work there after I earn my bachelor's degree because they did not have any professional to teach guidance there. More importantly, he was willing to give me a double salary for my work per month. This is really fascinating to me although I did not agree on it eventually (sic). (D-033)

It is a bad situation in Taiwan now because of low income problem. However, NSPC are developing. If they can guarantee that international students who study in there may obtain more employment opportunities and well compensation after graduation, this may be an incentive for us to study abroad in NSPC. (A-035)

\subsubsection{Personal Factors}

Most students attached importance to whether their experiences can be broadened by studying abroad in NSPC. As Student F-072 pointed out:

I definitely will take the factor into my consideration, namely whether this studying abroad experience can broaden my horizon. It is means that, through this experience, whether you can have more opportunities of experiencing local culture there, obtain more understanding of the academic development situation there, and even accumulate learning experience and knowledge there? If it is not, why you have to go studying abroad? (sic)

Notably, most students had a positive perspective toward this sub-factor. They thought that no matter which host country they chose, the experience would be an important one. They thought that studying abroad would give them more opportunities to live and learn together with local and other international students. They saw these experiences as being quite different from their experiences in Taiwan. Therefore, they believed these experiences 
would assist them to broaden their horizons. As Student A-092 stated:

If I can possess the opportunity of studying abroad, I want to go there and observe how they cultivate their students. For me, I think their learning environment is good for them to cultivate various competencies. Take language learning as an example, they can speak not only their mother language well but also other languages. I want to experience and have a look to this environment. If I can interact with the local students there for a long time, I will obtain more understanding of their cultures and value systems. These all are helpful for broadening my horizon (sic).

In addition, some students mentioned that an important consideration is whether studying abroad in NSPC would be beneficial for their future career development (i.e. employment). As Student E-094 said:

If we want to study abroad, something definitely should be considered is whether earning the degree (i.e. diploma) is beneficial for your future career development? If you can obtain the same benefits by studying in Taiwan, why you have to study abroad in other countries? (sic)

Notably, this sub-factor is more important for the students who want to search for jobs after graduation.

Given that Taiwan's government is promoting the NSP and NSPC are experiencing a period of strong economic development, if more students chose to study abroad in those countries, they could gain greater understanding of aspects such as culture, habits and customs, national development, educational policy, language usage, etc. This would be beneficial for students to obtain more future employment opportunities after graduation, whether in Taiwan or NSPC. Accordingly, they considered this a benefit of studying abroad in NSPC. As three students A-017 and H-077 shared:

Currently, many countries around the world are investing in NSPC; therefore, not only the situations of economic development there are vigorous, but also talents around the world are gathering there. I think if I can study in these NSPC, perhaps I could establish my social networking there. More importantly, because I can learn these local languages and have well adaptation there during the process of studying abroad, I have an advantage over others who do not study abroad there. These may be helpful for me to find jobs after graduation, and I think it is a good decision for my future career development (sic). (A-017)

If I want to search for jobs after graduation directly, it will be important for me that whether this studying abroad experience is helpful for my career development. Currently, I consider that, although the academic aspects of universities in NSPC are not appealing to me, this is still important for me that you can obtain more understandings of these countries by studying abroad there, such as culture, policy, habits and customs, local language learning, etc. More importantly, you always can get ahead of the competition if you study in there. This may be helpful for my career development (sic). (H-O77)

According to the results in this study, the authors would like to note that there is no single factor which can fully influence the students' decisions for studying abroad in NSPC; however, all of the factors are interacting with each other. In this regard, students' decisions regarding studying abroad are based on the complementary considerations of macro and micro factors; moreover, the weighting of these issues may be varied by students' economic sources, language skills, levels of study, countries of origin, and so forth.

\subsubsection{Suggested Improvements in the NSP}

Many students pointed out that Taiwanese society has some negative impressions, for example low economic development, low living standards, poor cultural and educational levels, etc.) about most NSPC, except for some countries at a higher level of economic development such as Singapore, Malaysia, Australia, and New Zealand. Therefore, these impressions may have a negative impact on students' willingness to study abroad in NSPC. As Student A-135 mentioned:

In Taiwan, a lot of employees came from NSPC. However, we treat them in a negative attitude; for instance, most Taiwanese consider that, these NSPC need our help and we do not rely on them. I think this is a bias to these countries, and it may cause Taiwanese students to doubt why we have to study abroad in these countries with worse economic development. Moreover, I think our country also treats these employees of NSPC impolitely. We often provide them labor-consuming jobs and put them to a lower level. These may construct an impression to us that they are second class labors and even these NSPC are inferior." Therefore, I suggested that, Taiwanese government should assist public to establish positive images toward NSPC by some strategies such as promotions and multicultural education, thereby enhancing Taiwanese students' willingness to study abroad in NSPC (sic).

Moreover, many Taiwanese students also thought that academic factors are important for them when it comes to 
whether to study abroad in NSPC. However, they generally did not seem to understand relevant academic aspects of these countries, such as academic strengths, the status of universities and colleges, the amount of investment in education, etc. Notably, they are not capable of searching for relevant information related to academic status of these countries due to the inability to understand their languages. To sum up, the above may have a significant negative impact on their motivation toward studying abroad in NSPC. Therefore, to attract more Taiwanese students, many respondents suggested that the Taiwanese government could provide more information regarding the academic aspects of NSPC. For instance, the government could create websites presenting relevant academic information for Taiwanese students who are interested in studying abroad in NSPC. As two students, E-137 and B-122, mentioned:

Notably, I think most students definitely consider what are the popular and prominent majors in these countries? However, just like what I told you that most students cannot find enough information through the internet in views of the situation that they are incapable of understanding the languages or words of these countries. Hence, I will suggest that, Taiwanese government should build an official website where some information regarding academic development of these countries could be provided such as the prominent or potential majors in these countries, the information regarding universities or colleges in these countries, the status of academic development of these countries, etc. This information will be beneficial for applying for studying abroad in there (sic). (E-137)

If I really want to study abroad in NSPC in view of the situation that they have limited understanding to them, I may suggest that Taiwanese government should inform me that what are the prominent or suggested majors (e.g., departments or programs) in these countries? And this question, what the benefits I will receive If I study in there, should be clarified. However, I have to say that, currently I cannot search for relevant information as I mentioned. It is pitiful to me. And I think our government should do something for what I said; otherwise I have no idea about why studying abroad in there (sic). (B-122)

Some students also mentioned that to attract more Taiwanese students to study abroad in NSPC and thereby promote talent exchange between Taiwan and these countries, future employment security should be emphasized. Some students suggested that Taiwan's government could negotiate agreements or somehow cooperate with the NSPC around employment security, thereby guaranteeing that students could find jobs in these countries after graduation. The government could also provide employment opportunities to these students directly. For example, the government could collaborate with relevant private companies in Taiwan or set up positions in public administration to prioritize employment opportunities for the students who graduated from universities or colleges in NSPC. These could all increase students' willingness to study abroad in these countries. As one student explained:

Many students have to find jobs after graduation from host countries; therefore, I suppose that, If Taiwanese government could provide more employment security and advantages to students who graduates from NSPC' universities or colleges, such as working in companies of NSPC. This will be an appealing factor for students to study abroad there. I also think that, because new southbound policy is just being implemented, the cooperation model between our country and these NSPC may be not developed yet. Hence, this may cause that students worry about their future employment security. However, if government could attach importance to this issue, this may attract students to study abroad there, thereby consolidating the talent exchange and talent cultivation (sic). (C-099)

\section{Discussions and Conclusions}

This study adopted a mixed methods approach to exploring Taiwanese students' attitudes and choice factors regarding studying abroad in NSPC. The results revealed that Taiwanese students generally have low willingness to study abroad in NSPC, except for Singapore, Australia, and New Zealand. Moreover, among six main categories of factors, three categories - academic, economic and personal - are more important to Taiwanese students than the other three factors - social, political and cultural - when considering whether to study abroad in NSPC.

As for the most important category, academic factors we found that Taiwanese students generally have not only limited understanding of the relevant academic aspects of universities and colleges in NSPC, but also consider the academic reputation or performance of these institutions to be sub-standard in comparison to universities and colleges in the United States and Europe. This has a negative impact on their willingness to study abroad in NSPC. However, the results of this study are different from those of a previous study conducted by Ma (2014). Ma found that academic factors are not important for students of developed countries who want to study abroad in developing countries. In this regard, we argued that, because Taiwan remains a diplomaism country (Liu, 
2013), Taiwanese students still attach importance to academic aspects of the universities and colleges of host countries (e.g., academic reputation, academic performance, investment in education, the value of diploma, etc.)

We also found that the programs or courses offered by universities and colleges in NSPC are important choice factors. Taiwanese students attached importance to the provision of English courses and programs, which echoed with the result shown in a relevant study (Eder, Smith, \& Pitts, 2010). It is because most Taiwanese students are not familiar with the local languages of NSPC, as opposed to English. If they want to study in these countries, improving their English language skills may be a way for them to learn something and to communicate with other international students more easily while studying abroad. Moreover, English is a universal language in the world; however, Taiwanese students' English language level is not high enough generally (Education First, 2017). If students can advance their English language level in the process of studying abroad or migration, their language capitals will be increased (Bauder, 2012), thereby enhancing their employment competitiveness and international mobility also (Karunaratne, 2014; Vu \& Burns, 2014). Therefore, it is an important choice factor for Taiwanese students that whether the English programs or courses are offered by universities and colleges in NSPC. Although they expressed preferences for English courses, we also found that they also expected to learn local languages through courses provided in universities and colleges of NSPC. This is probably because NSPC are currently experiencing rapid economic growth. The World Economic Forum anticipates that collectively, ASEAN will become the fifth largest economy in the world by 2020 (Cheok, 2017; Tso \& Jung, 2018). Therefore, if universities and colleges in NSPC provide some opportunities to learn local languages, Taiwanese students might be attracted to the opportunity to accumulate language and cultural capital in these NSPC, thereby enhancing their opportunities to remain in these high-growth countries after graduation (Xu \& Xu, 2015).

The results of this study indicate that personal factors are also important for students' decisions to study abroad in NSPC. They generally expected that such a study abroad experience could broaden their horizons and expand their future career opportunities. In this regard, a previous study indicated that studying abroad could be helpful for students in accumulating cultural and social capital in host countries. (Jupiter et al., 2017). Therefore, this factor may be beneficial for students who want to study abroad in NSPC, especially for the students who want to search for jobs after graduation.

Moreover, the results of this study indicate that economic factors are also important for Taiwanese students' willingness to study abroad in NSPC. Whether or not they could receive enough scholarships or grants is an important consideration for their decisions. These results are consistent with those of a previous study conducted by Ma (2014). This study found that Taiwanese students also attached importance to whether their job prospects in NSPC were improved after graduation. The above factors toned to be given greater consideration if the Taiwanese government is to be successful in encouraging more Taiwanese students to study abroad in NSPC.

Compared to the above main factors, the following two factors were seldom mentioned by Taiwanese students when considering studying abroad in NPSC: social factor and political factor. Why are social factors not a high priority for Taiwanese students when considering studying abroad in NSPC? There are several possible explanations. First, Taiwan is not that far from most southbound countries. In addition, the climate conditions in these countries are like those in Taiwan. Hence, Taiwanese students may not consider these factors to be very influential in their decision about whether to study in these countries. Second, because the number of Taiwanese students who study abroad in NSPC is low, and even declining, Taiwanese students who study abroad in these countries cannot easily establish interpersonal networks. This reduces the impacts of reference groups, for example friends and older brothers or sisters who are studying in universities in NSPC, in attracting Taiwanese students to study there, as well (James-MacEachern \& Yun, 2017). Therefore, they do not regard this sub-factor as important when considering studying abroad there.

There are also several possible explanations for why political factors do not play a significant role in students' decisions either. The status of diplomatic relations between home country and host country is the main sub-factor in the category of political factors. Although there are not formal diplomatic relations between Taiwan NSPC, people-to-people contact, economic relations and trade between Taiwan and NSPC are significant. The number of Taiwanese who travel to NSPC was 2.47 million in 2017, which accounted for $15.81 \%$ of the outbound travel of Taiwanese. Moreover, among the total number of inbound visitors, the number of tourists from NSPC accounted for $21.27 \%$ of tourists to Taiwan in 2017. Taiwan is the tenth largest export market and seventh largest import market for ASEAN (Jing, 2018). The movements of people, as well as goods and services indicate strong relations between Taiwan and NSPC. Therefore, the status of diplomatic relations is not a very important factor to Taiwanese students when considering studying abroad in NSPC. 


\section{Reference}

Altbach, P. G., \& Knight, J. (2007). The internationalization of higher education: Motivations and realities. Journal of Studies in International Education, 11(3-4), 290-305. https://doi.org/10.1177/1028315307303542

Bauder, H. (2012). The international mobility of academics: A labour market perspective. International Migration, 53(1), 83-96. https://doi.org/10.1111/j.1468-2435.2012.00783.x

Bond, T., \& Fox, C. (2007). Applying the Rasch model: Fundamental measurement in the human sciences (3rd ed.). Mahwah, NJ: Lawrence Erlbaum Associates.

Chang, F. C., \& Yu, M. N. (1999). The factors of study abroad interactions between Asian overseas students and the United States. Journal of Education \& Psychology, 22, 213-250.

Chang, Y. W., \& Lin, W. Y. (2003). Diplomaism or need for educational opportunity? - The social meaning of competition for school admission. Bulletin of Educational Psychology, 35(2), 167-182.

Chen, L. H. (2006). Attracting East Asian students to Canadian graduate schools. Canadian Journal of Higher Education, 36(2), 77-105.

Chen, L. T. (2011). A study of Mainland China student to take high education in Kinmen (Unpublished master's thesis). National Kinmen University, Kinmen.

Cheok, M. (2017). Fifty years on, Southeast Asia emerges as global growth leader. Retrieved from https://www. bloomberg.com/news/articles/2017-08-06/fifty-years-on-southeast-asia-emerges-as-global-growth-leader

Cresswell, J. W., \& Clark, V. L. P. (2007). Designing and conducting mixed methods research. London: Sage Publications.

Eccles, J. S., \& Wigfield, A. (2002). Motivational beliefs, values, and goals. Annual Review of Psychology, 53, 109-132. https://doi.org/10.1146/annurev.psych.53.100901.135153

Eder, J., Smith, W. W., \& Pitts. R. E. (2010). Exploring factors influencing student study abroad destination choice. Journal of Teaching in Travel and Tourism, 10(3), 232-250.

Education First. (2017). EF English proficiency index. Retrieved from https://www.ef.com/_/ /media/centra lefcom/epi/downloads/full-reports/v7/ef-epi-2017-chinese-traditional-tw.pdf

James-MacEachern, M., \& Yun, D. (2017). Exploring factors influencing international students' decision to choose a higher education institution: A comparison between Chinese and other students. International Journal of Educational Management, 31(3), 343-363. https://doi.org/10.1108/IJEM-11-2015-0158

Jing, B. J. (2018). Taiwan's regional strategy in Southeast Asia: Kicking the New Southbound Policy into high gear. Retrieved from http://www.nbr.org/downloads/pdfs/psa/jingbo_jiun_brief_013018.pdf

Jupiter, H., Othman, I. W., Suki, N. M., Yusoff, M. S., Awang, H., \& Razak, R. A. (2017). Factors influencing international student's decision in choosing study destination abroad. Labuan e-Journal of Muamalat and Society, $11,86-97$.

Karunaratne, S. K. (2014). Student perceptions on learning English for personal and career development. International Journal of English Literature and Culture, 2(10), 250-256. https://doi.org/10.14662/IJELC2014.063

Knight, J. (2006). Internationalization: Concepts, Complexities and Challenges. In J. J. F. Forest, \& P. G. Altbach (Eds.), International Handbook of Higher Education (pp. 207-227). Dordrecht, NL: Springer.

Li, M., \& Bray, M. (2007). Cross-border flows of students for higher education: Push-pull factors and motivations of mainland Chinese students in Hong Kong and Macau. Higher Education, 53, 791-818. https://doi.org/10.1007/s10734-005-5423-3

Lin, H. M. (in press). The Motivations and Strategies of New Southbound Policy Countries' Students for Studying and Working in Taiwan. Paper presented at Sixth "Young Scholars Workshop" at the CCKF-ERCCT.

Lin, P. (2012). Imaginated mobility: Taiwanese students studying in China. Mainland China Studies, 55(3), 57-83.

Linacre, J. M. (2006). A user's guide to WINSTEPS Rasch model computer program. Chicago, IL: Winsteps.

Ma, S. (2014). Understanding the social construction of international students' migration decisions through the study choices of foreign students in Taiwan. Journal of Population Studies, 48, 43-94. 
MacGregor, K. (2016, August 27). South catching up with North as student destination. Retrieved from http://www.universityworldnews.com/article.php?story=20160826141229255

Merriam, S. A. (2002). Qualitative research in practice. Examples for discussion and practice. San Francisco, CA: Jossey-Bass

Military of Education. (2017). Regulations regarding international students undertaking studies in Taiwan. Retrieved from http://edu.law.moe.gov.tw/EngLawContent.aspx?lan=E\&id=288\&KW=\%E5\%A4\%96\%E5\% 9C\%8B\%E5\%AD\%B8\%E7\%94\%9F\%E4\%BE\%86\%E8\%87\%BA\%E5\%B0\%B1\%E5\%AD\%B8\%E8\%BE $\% \mathrm{~A} 6 \% \mathrm{E} 6 \% \mathrm{~B} 3 \% 95$

Nguyen, C. H. (2017). The (dis)embodiment of human capital development projects: The case of Vietnam before and within the global "race for talent". International Social Science Journal, 220, 123-136.

OECD. (2007). Human Capital: How what you know shapes your life. Retrieved from https://www.oecd.org/insights/37967294.pdf

Okoli, C., \& Pawlowski, S. D. (2004). The Delphi method as a research tool: An example, design considerations and applications. Information and Management, 42(1), 15-29. https://doi.org/10.1016/j.im.2003.11.002

Silverman, D. (2015). Interpreting qualitative data (5th ed.) London, UK: Sage Publications.

Sim, J., \& Wright, C. C. (2005). The kappa statistic in reliability studies: use, interpretation, and sample size requirements. Physical therapy, 85(3), 257-268.

Sung, Y. T., \& Pan, P. Y. (2010). Applications of mixed methods research in educational studies. Journal of Research in Education Sciences, 55(4), 97-130.

Szelényi, K. (2006). Students without borders? Migratory decision making among international graduate students in the U.S. In P. Smith, \& F. Adrian (Eds.), The human face of global mobility: International highly skilled migration in Europe, North America and the Asia-Pacific (pp. 181-209). New Brunswick: Transaction Publishers.

Tso, C. D., \& Jung, G. (2018). Taiwan's New Southbound Policy: One-year economic performance review. Retrieved from http://www.nbr.org/downloads/pdfs/psa/tso_jung_brief_011818.pdf

Vu, N. T. T. \& Burns, A. (2014). English as a medium of instruction: Challenges for Vietnamese tertiary lecturers. The Journal of Asia TEF, 11(3), 1-31.

Wigfield, A., \& Eccles, J. S. (2000). Expectancy-value theory of achievement motivation. Contemporary Educational Psychology, 25, 68-81. https://doi.org/10.1006/ceps.1999.1015

Wolcott, H. (2008). Writing up qualitative research (3rd ed.). Thousand Oaks, CA: Sage.

Wu, Y. F., \& Lan, P. C. (2012). Taiwanese students pursuing higher education in China: Institutional frameworks and migration trajectories. Taiwanese Journal of Sociology, 50, 1-56.

$\mathrm{Xu}, \mathrm{Y} . \mathrm{J} .$, \& Xu, L. (2015, November). Cultural capital theory and college students' cultural competitiveness. Paper presented at International Conference on Mechanical Science and Engineering (ICMSE2015). Abstract retrieved from https://download.atlantis-press.com/article/25851315.pdf

Yang, A. H. (2017). Revisiting Taiwan's new southbound policy: Agenda, networks and challenges. Issues and Studies, 56(1), 123-143.

\section{Copyrights}

Copyright for this article is retained by the author(s), with first publication rights granted to the journal.

This is an open-access article distributed under the terms and conditions of the Creative Commons Attribution license (http://creativecommons.org/licenses/by/4.0/). 